\title{
'Crowded suburbs' and 'killer cities': a brief review of the relationship between urban environments and mental health
}

\author{
Helen L. Berry \\ National Centre for Epidemiology \& Population Health, \\ The Australian National University \\ Email:helen.berry@anu.edu.au
}

\begin{abstract}
Most of the world's population now lives in cities, with $90 \%$ of Australians living in urban settlements of more than 10000 people. Urban environments help shape population health, particularly among disadvantaged people, where poor health is concentrated. A growing body of research has focussed on the association between cities and mental health. Three hypotheses have been proposed to explain this association: psychosocial stressors; concentrated disadvantage; and social drift. It remains unclear, however, how the characteristics of urban environments are related to each other and to mental health, and what might be the pathways underpinning the experience of different individuals. With one in five Australian adults meeting the diagnostic criteria for a mental disorder each year, investigation of the relationship between urban environments and mental health is urgently needed. This paper briefly reviews recent studies linking disadvantaged urban environments with mental health and proposes a hypothetical model to help guide future research.
\end{abstract}

Half of the world's people now live in cities; ${ }^{1}$ by 2030 this proportion will increase to nearly two thirds. ${ }^{2}$ In Australia, $75 \%$ of people already live in cities with a population of more than 80000 and $90 \%$ live in urban settlements of 10000 or more. ${ }^{3}$ There is growing concern expressed in the media over the possible health-damaging effects of city life, including commentary on the dangers of 'crowded suburbs', ${ }^{4}$ a facet of modern 'killer cities'. Cities are a 'potentially powerful force' 6 in shaping population health, particularly that of disadvantaged people. ${ }^{7}$ The aims of this paper are to review briefly studies linking disadvantaged urban environments with poor mental health and to propose an explanatory model to guide future research.

Cities differ substantially from one another, as do neighbourhoods within cities. ${ }^{8-10}$ Poor health is often 'highly concentrated' in a small proportion of neighbourhoods ${ }^{11}$ that share health-damaging characteristics: ${ }^{12}$ inadequate or 'substandard' housing ${ }^{12,13}$ that limits access to shelter, connectedness, and a sense of 'home', ${ }^{14}$ including pride in one's home and home as a refuge; ${ }^{15}$ poor access to transport, co-location with 'undesirable land uses', such as bus depots and busy roads, ${ }^{12}$ lack of access to healthy food and overexposure to unhealthy food, alcohol and tobacco; ${ }^{7}$ limited access to and poor design of recreational and green spaces; and exposure to the clearly visible symbols of poverty and degradation ${ }^{16}$ that send 'powerful messages' that nobody cares about the neighbourhood or its residents. ${ }^{12}$ These characteristics generate direct health risks, for example, by facilitating the spread of disease and discouraging physical activity, ${ }^{8}$ while encouraging negative health behaviours, such as reduced health care-seeking. ${ }^{16}$

While most studies have examined cities and their effects on physical health, some have investigated mental health. Mental health problems have been associated with social disorganisation and living in deprived neighbourhoods. ${ }^{6}$ Increasing population density has also been linked to mental health problems, including elevated rates of psychosis and depression. ${ }^{17-19}$ However, density alone does not necessarily determine disadvantage: for example, Potts Point in Sydney and Southbank in Melbourne are densely populated areas associated with advantage rather than disadvantage. More likely, population density is health damaging when it occurs in conjunction with other risk factors in the physical and social environment. These include lack of access to the natural environment and, especially, high levels of socio-economic deprivation, ${ }^{20}$ including overcrowding. ${ }^{21}$ Prospective studies have concluded that improvements in the built environment are associated with decreasing psychiatric morbidity. In a follow-up of 503 people in Oslo, Norway, mental health problems declined among participants living in an initially poorly functioning neighbourhood that improved over a decade. $^{22}$ Relocation can achieve similar results. In the American 'Moving to Opportunity' study, families selected at random moved from deprived to non-deprived 
neighbourhoods. ${ }^{23}$ In 550 such families, three years later, parents were less distressed and sons less anxious and depressed than were their peers who remained in public housing.

Qualitative studies of urban renewal and mental wellbeing have corroborated epidemiological findings. Indepth interviews with 16 Londoners indicated that enhanced safety and community facilities were associated with improved daily coping. ${ }^{24}$

\section{Health-damaging characteristics of urban environments}

Built environments may be conceptualised in terms of ecological (neighbourhood) characteristics, such as type of housing, roads and public places, ${ }^{25}$ and of individual dwellings. Disadvantaged neighbourhoods exhibit substandard housing, ${ }^{12}$ which has been directly linked to poor mental health, ${ }^{26,27}$ and 'physical incivilities'. ${ }^{25}$ These physical incivilities include derelict buildings, extensive graffiti, litter, vandalism, excessive traffic, urine, dog faeces, a small proportion of private gardens (and a correspondingly higher proportion of shared recreational spaces), ${ }^{25}$ visibly deteriorating buildings, external walls, windows, stairs or lifts, structural fires and dirty streets or pavements. ${ }^{6}$

Substandard housing is most prevalent in poor neighbourhoods $^{25}$ and among dwellings built since 1970, with deck access (a means of access to flats above ground level via stairs or lifts that lead to long corridors onto which residents' front doors open directly) or floor-level access. This type of housing features one or more structural problems: damp, ${ }^{13}$ leaking roofs, rot, pests, ${ }^{25}$ toilet breakdown, nonfunctioning kitchens, inadequate heating, repeated heating breakdown during winter, peeling plaster or paint, internal leaks, ${ }^{6}$ overheating in summer ${ }^{13}$ and lack of affordability. ${ }^{11,15}$ People's perceptions about their housing may be influenced by their neighbourhood, and negative perceptions about both incline people to relocate, increasing residential instability. ${ }^{28}$ This breaks social ties that promote mental health. ${ }^{29}$

Disadvantaged social environments exhibit social incivilities, such as the presence of crime, teen gangs, ${ }^{25}$ noise (for example, from trucks and aeroplanes ${ }^{30}$ ), foul air, ${ }^{27}$ neighbourhood poverty ${ }^{6}$ and diminished social capital. Sociodemographic disadvantages also prevail, including overcrowding, unemployment, poor education, single parenting, ethnicity, renting, no car or van access, ${ }^{25}$ poverty ${ }^{6}$ and being an immigrant or refugee. ${ }^{17}$

The built and social environments and mental health are entwined. 6,25 In a study of 1887 residents of two London wards, people living with socio-demographic disadvantages, substandard housing and physical incivilities were more likely to report depression than were their less dis- advantaged peers. ${ }^{25}$ Even after adjusting for socio-demographic characteristics and attributes of individual dwellings, significant associations remained between depression and deck access, post 1970s housing and few private gardens. Similar findings emerged from a study of depression and the built environment in 59 neighbourhoods in New York City. ${ }^{6}$ Controlling for socio-demographic factors, substandard housing and physical incivilities were significantly associated with elevated rates of depression.

\section{How do cities influence mental health?}

Three explanations for the direct and indirect ${ }^{2}$ associations between urban environments and mental health have been proposed: ${ }^{6}$ psychosocial stressors, concentrated disadvantage and social drift.

\section{Psychosocial stressors}

Pearlin and colleagues ${ }^{31}$ described 'the stress process' as negative life events creating strain in people's lives, with this strain eroding positive self-concepts such as confidence and sense of worth, leaving people psychologically vulnerable, especially to depression. Exposure to physical and social incivilities in cities generates psychosocial stress; both are associated with diminished feelings of safety and security in one's home, which is related to mental health. ${ }^{15}$

\section{Concentrated disadvantage}

The concentrated disadvantage explanation suggests that the density of city populations concentrates physical and social problems, intensifying their effects and inflating pressures on mental health. Consistent with this explanation, physical incivilities, substandard housing, social incivilities and socio-demographic disadvantage are significantly positively correlated, as are their constituent components. ${ }^{6,25}$ The mental health effects of concentrated disadvantage may be mediated by psychosocial factors, such as collective efficacy ${ }^{32}$ and loss of control, social support, and recreation. ${ }^{27}$

\section{Social drift}

The social drift explanation proposes that the socioeconomic circumstances of people with severe and enduring mental health problems gradually deteriorate, necessitating relocating into progressively disadvantaged neighbourhoods and lower quality accommodation. ${ }^{33}$ This explanation does not preclude the possibility that disadvantaged urban environments might also contribute to mental health problems. Indeed, while social drift contributes to the concentration of psychosis in disadvantaged neighbourhoods, urban environment causation seems more important than selection; ${ }^{19}$ controlling for individual income and neighbourhood socio-economic status, a relationship has been found between the urban environment and depression. ${ }^{6}$ 


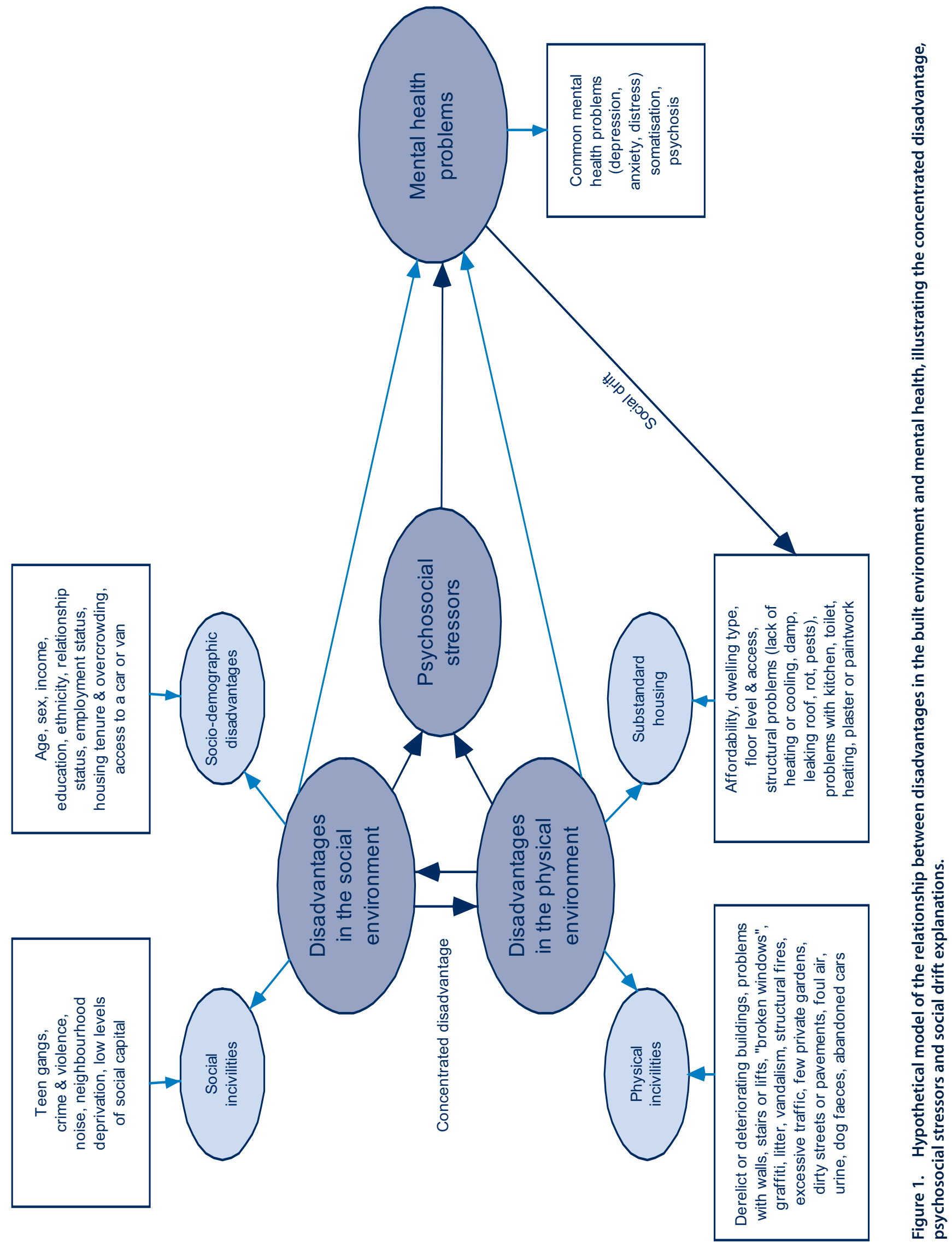




\section{Cities and mental health: a conceptual model}

While there is evidence that built environments may influence mental health and that mental health problems predispose people to live in disadvantaged environments, it is unclear exactly how environmental and social factors are related and how different explanatory hypotheses might be accommodated within a pathways model that allows for different individual experience. Figure 1 is a conceptual model of how disadvantaged city environments might be linked to mental health problems. The Figure includes only factors for which there is direct empirical evidence for a link with mental health, as summarised in the literature review above.

Constructs (in ellipses) have been presented together with lists of factors (in boxes) that have been empirically associated with the built environment and mental health. Darker arrows denote the direction of relationships among constructs as suggested by the concentrated disadvantage, psychosocial stressors and social drift explanations. ${ }^{6}$ Lighter arrows indicate relationships for which there is empirical evidence but which do not feature in the three explanations. The explanations are not mutually exclusive. ${ }^{6}$ Instead, they describe different aspects of a bigger picture, which must also take account of the size, density, diversity and complexity of a city's population and its global, national, political, economic and social contexts. ${ }^{1}$

\section{Urban environments and mental health: an urgent research priority}

One in five Australian adults meets the diagnostic criteria for a mental disorder each year, ${ }^{34}$ with mental health problems (particularly depression and anxiety ${ }^{35}$ ) being the leading cause of non-fatal disease burden. ${ }^{36}$ The prevalence of mental health problems is increasing. ${ }^{37-39}$ This trend is likely to continue, ${ }^{40}$ involving massive costs to healthcare ${ }^{41-45}$ and Australian society, ${ }^{42,46-52}$ with profound implications for the intergenerational transmission of mental health problems ${ }^{53-55}$ and disadvantage. ${ }^{56}$ Though we live predominantly in cities, ${ }^{30,57}$ we do not fully understand how cities influence mental health; ${ }^{58}$ the social environment's contribution to this relationship remains 'neglected' in research as a 'possible [explanatory] mechanism'. ${ }^{18}$ The fields of social ecology and community psychology, together with social capital theory, could usefully contribute to filling this gap.

It is essential ${ }^{59}$ to begin systematic investigation of pathways models that describe how features of the social and built environments of Australian cities may be related to mental health. Urban environments are amenable to modification and, with the potential to affect vast proportions of the world's population, ${ }^{2}$ this is urgently needed..$^{11,13}$ Insufficient investment has been made ${ }^{27}$ in the challenging $\operatorname{task}^{60}$ of developing sophisticated conceptual frameworks (pathways models) of how the built environment may affect mental health. Frameworks must (i) be theorybased, empirically tested and continuously refined, ${ }^{60}$ (ii) be constructed within a population health approach, with prevention in mind, and with interventions evaluated via 'report card[s]' that are not reliant on primary data collection and are 'grounded' in local realities, ${ }^{10}$ and (iii) include health-promoting features of built environments, such as contact with nature ${ }^{61,62}$ and easy access to parks and walking. ${ }^{58,60,63}$

\section{References}

1. Galea S, Freudenberg N, Vlahov D. Cities and population health. Soc Sci Med 2005; 60(5): 1017-33.

doi:10.1016/j.socscimed.2004.06.036

2. Vlahov D, Galea S. Urban health: A new discipline. Lancet 2003; 362(9390): 1091-2. doi:10.1016/S0140-6736(03)14499-6

3. Newton PW, Baum S, Bhatia K, Brown SK, Cameron AS, Foran B. et al. Human settlements. In: Australia State of the Environment Report 2001 (Theme Report). Canberra: Department of the Environment and Heritage, 2001.

4. Dick T. Crowded suburbs make you depressed, but urban sprawl makes you fat. In: The Sydney Morning Herald. 9 December 2004.

5. Robotham J, Nixon S. Killer cities. In: The Sydney Morning Herald. 12 August 2006.

6. Galea S, Ahern J, Rudenstine S, Wallace Z, Vlahov D. Urban built environment and depression: A multilevel analysis. J Epidemiol Community Health 2005; 59(10): 822-7. doi:10.1136/jech.2005.033084

7. Bashir SA. Home is where the harm is: Inadequate housing as a public health crisis. Am J Public Health 2002; 92(5): 733-8.

8. Galea S, Vlahov D. Urban health: Evidence, challenges, and directions. Annu Rev Public Health 2005; 26(1): 341-65. doi:10.1146/annurev.publhealth.26.021304.144708

9. Grimm NB, Grove JM, Pickett STA, Redman CL. Integrated approaches to long-term studies of urban ecological systems. Bioscience 2000; 50(7): 571. doi:10.1641/00063568(2000)050[0571:IATLTO]2.0.CO;2

10. Strike C, Goering P, Wasylenki D. A population health framework for inner-city mental health. $J$ Urban Health 2002; 79(4)(Suppl. 1): S13-20.

11. Kingsley GT. Housing, health, and the neighborhood context. Am J Prev Med 2003; 24(3)(Suppl. 1): 6-7. doi:10.1016/S0749-3797(02)00651-7

12. Frumkin H. Health, equity, and the build environment. Environ Health Perspect 2005; 113(5): 290-1.

13. Krieger J, Higgins DL. Housing and health: Time again for public health action. Am J Public Health 2002; 92(5): 758-68.

14. Fullilove MT. What's housing got to do with it? Am J Public Health 2000; 90(2): 183.

15. Dunn JR. Housing and inequalities in health: A study of socioeconomic dimensions of housing and self reported health from a survey of Vancouver residents. J Epidemiol Community Health 2002; 56(9): 671-81. doi:10.1136/jech.56.9.671 
16. Cohen D, Spear S, Scribner R, Kissinger P, Mason K, Wildgen J. 'Broken windows' and the risk of gonorrhea. Am J Public Health 2000; 90(2): 230.

17. Sundquist K, Frank G, Sundquist JAN. Urbanisation and incidence of psychosis and depression: Follow-up study of 4.4 million women and men in Sweden. Br J Psychiatry 2004; 184(4): 293-8. doi:10.1192/bjp.184.4.293

18. Van Os JIM. Does the urban environment cause psychosis? Br J Psychiatry 2004; 184(4): 287-8. doi:10.1192/bjp.184.4.287

19. Krabbendam L, van Os J. Schizophrenia and Urbanicity: A Major Environmental Influence: Conditional on Genetic Risk. Schizophr Bull 2005; 31(4): 795-9. doi:10.1093/schbul/sbi060

20. Boyden S, Millar S, Newcombe K, O’Neill B. The ecology of a city and its people: the case of Hong Kong. Canberra: Australian National University Press, 1981.

21. Samiya AB. Home is where the harm is: Inadequate housing as a public health crisis. Am J Public Health 2002; 92(5): 733.

22. Dalgard OS, Tambs K. Urban environment and mental health. A longitudinal study. Br J Psychiatry 1997; 171(6): 530-6.

23. Leventhal T, Brooks-Gunn J. Moving to opportunity: An experimental study of neighborhood effects on mental health. Am J Public Health 2003; 93(9): 1576.

24. Whitley R, Prince M. Can urban regeneration programmes assist coping and recovery for people with mental illness? Suggestions from a qualitative case study. Health Promot Internation 2006; 21(1): 19-26. doi:10.1093/heapro/dai024

25. Weich S, Blanchard M, Prince M, Burton E, Erens BOB, Sproston K. Mental health and the built environment: Crosssectional survey of individual and contextual risk factors for depression. Br J Psychiatry 2002; 180(5): 428-33. doi:10.1192/bjp.180.5.428

26. Evans GW, Wells NM, Chan HYE, Saltzman H. Housing quality and mental health. J Consult Clin Psychol 2000; 68(3): 526-30. doi:10.1037/0022-006X.68.3.526

27. Evans GW. The built environment and mental health. J Urban Health 2003; 80(4): 536-55.

28. Kearns A, Parkes A. Living in and leaving poor neighbourhood conditions in England. Housing Stud 2003; 18(6): 827. doi:10.1080/0267303032000135456

29. Kawachi I, Berkman LF. Social ties and mental health. $J$ Urban Health 2001; 78(3): 458-67.

30. Riediker M, Koren HS. The importance of environmental exposures to physical, mental and social well-being. Int J Hyg Environ Health 2004; 207(3): 193-201. doi:10.1078/14384639-00284

31. Pearlin LI, Lieberman MA, Menaghan EG, Mullan JT. The stress process. J Health Soc Behav 1981; 22: 337-56. doi: $10.2307 / 2136676$

32. Sampson RJ, Raudenbush SW, Earls F. Neighborhoods and violent crime: A multilevel study of collective efficacy. Science 1997; 277: 918-24. doi:10.1126/science.277.5328.918

33. Rutter M, Madge N. Cycles of disadvantage: a review of research. London: Heinemann, 1976
34. Andrews G, Hall W, Teesson M, Henderson S. The mental health of Australians. Canberra: Mental Health Branch, Commonwealth Department of Health and Aged Care, 1999.

35. Tylee A. Depression in Europe: Experience from the DEPRES II survey. European Neuropsychopharmacology 2000; 10(Suppl. 14): S445-S448.

36. Mathers C, Vos T, Stevenson C. The burden of disease and injury in Australia. Canberra: Australian Institute of Health and Welfare, 1999.

37. Twenge JM. The age of anxiety? Birth cohort change in anxiety and neuroticism, 1952-1993. J Pers Soc Psychol 2000; 79(6): 1007-21. doi:10.1037/0022-3514.79.6.1007

38. Browne G, Gafni A, Roberts J, Byrne C, Majumdar B. Effective/efficient mental health programs for school-age children: A synthesis of reviews. Soc Sci Med 2004; 58(7): 1367-84. doi:10.1016/S0277-9536(03)00332-0

39. Langsford S, Houghton S, Douglas G, Whiting K. Prevalence and Comorbidity of Child and Adolescent Disorders in Western Australia Mainstream School Students. The International Forum for Psychiatry 2001; 8: 1-7.

40. Sartorius N. Social capital and mental health. Curr Opin Psychiatry 2003; 16(Suppl 2): S101-5. doi:10.1097/00001504200304002-00015

41. Garattini L, Barbui C, Clemente R, Cornago D, Parazzini F. Direct Costs of Schizophrenia and Related Disorders in Italian Community Mental Health Services: A Multicenter, Prospective 1-Year Followup Study. Schizophr Bull 2004; 30(2): 295-302.

42. Ingoglia CS. Caring for Persons With Mental Illness: Making Policy Decisions That Are Truly Cost-Effective. Drug Benefit Trends 2003; 15: 5 .

43. Knapp M. Hidden costs of mental illness. Br J Psychiatry 2003; 183(6): 477-8. doi:10.1192/bjp.183.6.477

44. D'Souza RM, Strazdins L, Broom DH, Rodgers B, Berry HL. Work demands, job insecurity and sickness absence from work. How productive is the new, flexible labour force? Aust N Z J Public Health 2006; 30(3): 205. doi:10.1111/j.1467842X.2006.tb00859.x

45. Lim D, Sanderson K, Andrews G. Lost productivity among full-time workers with mental disorders. J Ment Health Policy Econ 2000; 3(3): 139-46. doi:10.1002/mhp.93

46. Hodgins S. The major mental disorders and crime: Stop debating and start treating and preventing. Int J Law Psychiatry 2001; 24(4-5): 427-46. doi:10.1016/S01602527(01)00077-2

47. Hodgins S, Lalonde N. Major mental disorders and crime: Changes over time? In: Cohen P, Slomkowski C, editors. Historical and geographical influences on psychopathology. Mahwah, NJ, US: Lawrence Erlbaum Associates, Publishers, 1999. pp. 57-83.

48. Munkner R, Haastrup S, Jorgensen T, Andreasen AH, Kramp P. Taking cognizance of mental illness in schizophrenics and its association with crime and substance-related diagnoses. Acta Psychiatr Scand 2003; 107(2): 111-7. doi:10.1034/j.16000447.2003.02122.x

49. Nelson SH. Role of social disadvantage in crime, joblessness, and homelessness among persons with serious mental illness': Comment. Psychiatr Serv 2002; 53(5): 899-900. 
50. Putkonen A, Kotilainen I, Joyal CC, Tiihonen J. Comorbid personality disorders and substance use disorders of mentally ill homicide offenders: A structured clinical study on dual and triple diagnoses. Schizophr Bull 2004; 30(1): 433-42.

51. Droes RM, Breebaart E, Meiland FJ, Van Tilburg W, Mellenbergh GJ. Effect of Meeting Centres Support Program on feelings of competence of family carers and delay of institutionalization of people with dementia. Aging Ment Health 2004; 8(3): 201-11.

doi:10.1080/13607860410001669732

52. Highet NJ, McNair BG, Davenport TA, Hickie IB. 'How much more can we lose?' Carer and family perspectives on living with a person with depression. Med J Aust 2004; 181(7): S6.

53. Baydar N, Reid MJ, Webster-Stratton C. The role of mental health factors and program engagement in the effectiveness of a preventive parenting program for Head Start mothers. Child Dev 2003; 74(5): 1433-53. doi:10.1111/1467-8624.00616

54. Hinshaw SP. Parental mental disorder and children's functioning: Silence and communication, stigma and resilience. J Clin Child Adolesc Psychol 2004; 33(2): 400-11. doi:10.1207/s15374424jccp3302_22

55. Kilic EZ, Ozguven HD, Sayil I. The psychological effects of parental mental health on children experiencing disaster: The experience of Bolu earthquake in Turkey. Fam Process 2003; 42(4): 485-95. doi:10.1111/j.1545-5300.2003.00485.x

56. Berry HL, George E, Rodgers B, Butterworth P, Caldwell TM. Intergenerational transmission of reliance on income support: psychosocial factors and their measurement. Social policy research papers 31. Canberra: The Australian National University, 2007.

57. Satterthwaite D. Will most people live in cities? BMJ 2000; 321(7269): 1143-5. doi:10.1136/bmj.321.7269.1143

58. Srinivasan S, O'Fallon LR, Dearry A. Creating healthy communities, healthy homes, healthy people: Initiating a research agenda on the built environment and public health. Am J Public Health 2003; 93(9): 1446-50.

59. Jackson RJ. Habitat and health: The role of environmental factors in the health of urban populations. J Urban Health 1998; 75(2): 258-62. doi:10.1007/BF02345094

60. Northridge ME, Sclar ED, Biswas P. Sorting out the connections between the built environment and health: A conceptual framework for navigating pathways and planning healthy cities. J Urban Health 2003; V80(4): 556-68.

61. Frumkin H. Beyond toxicity: Human health and the natural environment. Am J Prev Med 2001; 20(3): 234-40. doi:10.1016/S0749-3797(00)00317-2

62. Berto R. Assessing the restorative value of the environment: A study on the elderly in comparison with young adults and adolescents. Int J Psychol 2007; 42(5): 331-41. doi:10.1080/00207590601000590

63. Maller C, Townsend M, Brown P, St Leger L. Healthy parks healthy people: report to Parks Victoria and the International Park Strategic Partners Group. In: Social and mental health priority area: Occasional paper series. Melbourne: Deakin University and Parks Victoria, 2002. 